Revista Ibero-Americana de Ciências Ambientais

Ibero-American Journal of Environmental Sciences

Edição Especial do Congresso de Gestão Ambiental do Baixo Amazonas

(CONGABA) Ago 2018 - v.9 - n.6

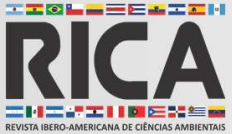

ISSN: 2179-6858

\title{
Valoração econômica contingente dos recursos ambientais do ecossistema manguezal em São Caetano de Odivelas (PA)
}

\section{Contingent economic valuation of the environmental resources of the mangrove ecosystem in São Caetano de Odivelas (PA)}

\begin{abstract}
The importance of environmental and natural resources for human life is increasingly evident. Mangrove ecosystem (s) are important for environmental balance and are considered the richest marine ecosystem after coral reefs. They are important not only for marine life and seawater quality, but also for countless other organisms that depend on it in their life cycle. In addition, the mangroves, through their crowns, sequester carbon dioxide (CO2) from the atmosphere, mitgating the greentouse effect, and serve as 'natural barriers' against erosion. However, the uncontrolled extraction of marine life, as happens in the RLSEX (conservation unit), the use of wood for firewood instead. Another threat is agriculture near the mangrove swamps, as rainwater inses the ground, carrying pesticides to the mangrove swamps. Pollution. in general, is another cause of mangrove loss in Brazil and worlduide Given the concern with the sustainability of this ecosystem, the environmental economic valuation is a fundamental tool in the formulation and evaluation of public policies oriented to sustainable development and the preservation of environmental (natural) resources of that ecosystem. The 'creation' of the hypothetical market involving direct and indirect uses and values and non-use of mangrove option and existence, respectively, was conceived with the purpose of proposing the constitution of a policy aimed at preserving the entire mangrove ecosystem, the which would be instituted in an income transfer in the form of environmental compensation, for families that would no longer have access to mangrove resources. This remuneration should correspond to the advisory value of direct and indirect uses and non-use - option and existence, minimum obtained from mangroves In addition, families should commit to preserving the mangroves by becoming the mangrove inspectors of their locality. The study proved that despite local empirical knowledge about ecosystem services, the combination of this with scientific knowledge provides better elicitation in the estimation of the economic values of use and, above all, of non-use of environmental resources, which generates a more significant estimate. in terms of VERA.
\end{abstract}

Keywords: Environmental economics; Economic valuation; Environmental resources; Ecosystem; Mangrove.

Topic: Valoração e Economia Ambiental

Reviewed anonymously in the process of blind peer
Received: 25/08/2018

Approved: $\mathbf{3 0 / 0 8 / 2 0 1 8}$
Abner Vilhena de Carvalho (iD)

Universidade Federal do Oeste do Pará, Brasil http://lattes.cnpq.br/8971980101556291

http://orcid.org/0000-0003-3501-6611

abnervilhena@hotmail.com

Maria de Nazaré do Carmo Bastos

Universidade Federal Rural da Amazônia, Brasil

http://lattes.cnpq.br/7398496891467878

nazir@museu-goeldi.br

Ely Simone Cajueiro Gurgel (iD)

Universidade do Estado do Pará, Brasil

http://lattes.cnpq.br/8003316810277307

http://orcid.org/0000-0002-9488-7532

esgurgel@museu-goeldi.br
Ana Yoshi Harada

Universidade Federal do Paraná, Brasil

http://lattes.cnpq.br/2403664119078137 ahara@museu-goeldi.br

Maria Ivete Herculano do Nascimento Universidade Federal da Paraíba, Brasil http://lattes.cnpq.br/5247574405616929 ivete@museu-goeldi.br

Maria Luiza Videira Marceliano Universidade Federal do Pará, Brasil http://lattes.cnpq.br/4201678009295335 mlvideira@hotmail.com
Maria das Graças Santana da Silva Universidade Federal do Pará, Brasil http://lattes.cnpq.br/1131087001804987 santana@museu-goeldi.br

Andreza de Lourdes Souza Gomes Universidade Federal do Pará, Brasil http://lattes.cnpq.br/4796866719891203 algomes@ufpa.br

DOI: $10.6008 / C B P C 2179-6858.2018 .006 .0037$

Referencing this:

CARVALHO, A. V.; BASTOS, M. N. C.; GURGEL, E. S. C.; HARADA, A. Y.; NASCIMENTO, M. I. H.; MARCELIANO, M. L. V.; SILVA, M. G. S.; GOMES, A. L. S.. Valoração econômica contingente dos recursos ambientais do ecossistema manguezal em São Caetano de Odivelas (PA). Revista Ibero-Americana de Ciências Ambientais, v.9, n.6, p.409-427, 2018. DOI: http://doi.org/10.6008/CBPC2179$\underline{6858.2018 .006 .0037}$ 


\section{INTRODUÇÃO}

A valoração econômica ambiental é uma ferramenta fundamental para a formulação e a avaliação de políticas públicas orientadas ao desenvolvimento sustentável e a preservação dos recursos ambientais. Esta é requerida ou desejada cada vez mais por gestores ambientais, estudantes de mestrado e doutorado e outros profissionais da área ambiental (CASTRO et al., 2010). Todavia, no Brasil, ainda são poucas as experiências com a utilização de métodos de valoração econômica ambiental para apoiar a formulação de políticas públicas, quando comparamos com os casos norte americano e europeu (ORTIZ, 2003).

A valoração econômica de recursos ambientais busca avaliar o valor econômico de um recurso ambiental através da determinação do que é equivalente, em termos de outros recursos disponíveis na economia, dos quais estariam os (seres humanos) dispostos a abrir mão de maneira a obter uma melhoria de qualidade ou quantidade do recurso ambiental. Em resumo, Ortiz (2003) afirma que "a valoração econômica de recursos ambientais é uma análise de trade-off's (escolha entre opções)".

A crescente atenção dada a valoração econômica ambiental tem impulsionado de forma significativa esta área de estudo, a qual hoje pode ser considerada uma área de fronteira da Ciência Econômica. A novidade aqui é a complexidade do tema, entretanto, têm induzido o profissional ou o estudante não economista a duas situações extrema (MOTTA, 1997): a uma de ceticismo que rejeita qualquer abordagem dita econômica devido a uma percepção quase sempre insuficiente da teoria econômica que fundamenta estas abordagens; e a outra na qual se adotam inadequadamente técnicas de valoração com base em procedimentos estimativos intuitivos que, quando não apropriados, aumentam ainda mais o ceticismo e a rejeição aos métodos adotados.

Um bem ou serviço ambiental qualquer tem grande importância para o suporte às funções que garantem a sobrevivência das espécies. De forma geral, todas as espécies de animais e vegetais dependem dos serviços ecossistêmicos dos recursos naturais para a sua existência. Essa importância traduz-se em valores associados aos bens ou recursos ambientais, que podem ser valores morais, éticos ou econômicos (ORTIZ, 2003).

Determinar o valor econômico de um recurso ambiental é estimar o valor monetário deste em relação aos outros bens e serviços disponíveis na economia. Todas as mercadorias têm valor econômico, pois têm preço fixado pelos mercados. Mas os recursos da biodiversidade, tais como um orangotango, uma floresta, o ar e tanto outros não tem preço fixado pelos mercados. Os recursos naturais não são mercadorias, constituem-se em ativos essenciais à preservação da vida e de todos os seres (MOTTA, 1997).

Entendendo que todo recurso ambiental têm um valor intrínseco que, definido em Ortiz (1993) "é o valor que the é próprio, interior, inerente ou peculiar. É o valor que reflete direitos de existência e interesse de espécies não humanas e objetos inanimados". Ressalta-se da existência na literatura de alguns métodos que procuram identificar valores intrínsecos de recursos ambientais de maneiras não relacionadas com a análise econômica, entretanto, do ponto de vista econômico, o valor relevante de um recurso ambiental é 
aquele valor para a tomada de decisão, ou seja, para um economista o valor econômico de um recurso ambiental é a contribuição do recurso para o bem estar social (MAY et al., 2003).

A importância dos recursos ambientais e naturais para vida humana está cada vez mais evidente. O(s) ecossistema(s) dos manguezais são importantes para o equilíbrio do meio ambiente, além de ser considerado o mais rico ecossistema marinho, depois dos recifes de corais. Eles são importantes não apenas para a vida marinha e a qualidade da água do mar, mas para inúmeros outros organismos que dependem dele no seu ciclo de vida. Além disso, o mangue através de suas copas, sequestram dióxido de carbono (CO2) da atmosfera amenizando o efeito estufa, além de servirem como 'barreiras naturais' contra a erosão (NANNI et al., 2005a).

Contudo, a extração descontrolada da vida marinha, como acontece nas RESEX (unidade de conservação), o uso da madeira para lenha e outros fins, o aterramento para a construção de casas de veraneio, marinas, portos, etc. e ainda a construção de fazendas marinhas, como as que criam camarão estão cada vez mais extirpando o(s) mangue(s) para, em seu lugar, criarem tanques de reprodução. Outra ameaça é a agricultura próxima ao manguezal, pois a água que caem das chuvas 'lavam' o chão, levando agrotóxicos até o mangue. A poluição, de forma geral, é outra causa da perda de mangues no Brasil e no mundo (LACERDA, 1984, citado em NANNI et al., 2005b)

Diante da preocupação com a sustentabilidade deste ecossistema, a valoração econômica ambiental apresenta-se como uma ferramenta fundamental para a formulação e avaliação de políticas públicas orientadas ao desenvolvimento sustentável e a preservação dos recursos ambientais (naturais) daquele ecossistema. Portanto, valorar através da 'criação' do mercado hipotético envolvendo os usos e valores diretos e indiretos e os não usos de opção e existência do manguezal respectivamente, é o objetivo principal desta pesquisa.

Deve-se ressaltar o objetivo definido acima foi concebido com a finalidade de propor a constituição de uma política visando preservar o ecossistema manguezal em sua totalidade, o qual se instituiria numa transferência de renda na forma de compensatória ambiental, para as famílias que deixariam de ter acesso aos recursos do manguezal. Esta remuneração deveria ser correspondente ao valor consultivo de usos mínimo obtido dos manguezais. Adicionalmente, as famílias deveriam se comprometer de preservar os manguezais, tornando-se os fiscais dos manguezais de sua localidade.

Os bens naturais e os serviços ecossistêmicos são de grande importância para a resiliência de setores econômicos como: agropecuário, energético, pesqueiro e florestal. Apesar do reconhecimento acerca da importância da biodiversidade e de ecossistemas saudáveis para o desenvolvimento econômico e social do país, isso ainda não se reflete plenamente na construção e implementação de políticas e decisões empresariais; nesse contexto, Mota (2001) afirma que "o enfoque sistêmico ${ }^{1}$ da valoração ajuda no entendimento de como é importante compreender o valor que tem o meio ambiente para a sobrevivência das espécies na terra".

\footnotetext{
${ }^{1}$ Maiores detalhes sobre o enfoque sistêmico dos recursos naturais em Mota (2006). 


\section{REVISÃO TEÓRICA}

Os diversos ecossistemas provêm uma gama de bens e serviços ambientais que geram benefícios diretos e indiretos para a sociedade, que em muitos casos, são providos gratuitamente. Embora muitos deles não tenham mercados que possam revelar seu valor, a sociedade atribui valor a esses bens por contribuir significativamente para seu nível de bem-estar, sobretudo, valores de opção e existência. Por esta razão, é importante saber como mudanças na qualidade e quantidade desses bens e serviços afetam o nível de bemestar das pessoas, que é o que a valoração econômica ambiental se propõe a fazer (CASTRO et al., 2010).

\section{Valor Econômico Total ou Valor Econômico dos Recursos Ambientais e os Principais Métodos de Valoração Econômica Ambiental}

Conforme discutido anteriormente, o valor econômico dos recursos ambientais geralmente não é observável no mercado através de preços que reflitam seu custo de oportunidade. Então, como identificar este valor econômico? Descreve Motta (1997) em sem manual que: primeiro, devemos perceber que o valor econômico dos recursos ambientais é derivado de todos os seus atributos; e segundo, que estes atributos podem estar ou não associados a um uso. Ou seja, o consumo de um recurso ambiental se realiza via uso e não uso. Um bem é homogêneo quando os seus atributos ou características que geram satisfação de consumo não se alteram.

Outros bens são, na verdade, parte de classes de bens ou serviços compostos. Nestes casos, cada membro da classe apresenta atributos diferenciados. Logo, o preço de uma unidade $j$ do bem $X_{i}, P_{x i j}$, pode ser definido por um vetor de atributos ou características, $a_{i j}$, tal que: $P_{x i j}=P_{x i j}\left(a_{i j 1} ; a_{i j 2} ; \ldots ; a_{i j n}\right)$. No caso de um recurso ambiental, os fluxos de bens e serviços ambientais, que são derivados do seu consumo, definem seus atributos. Entretanto, existem também atributos de consumo associados à própria existência do recurso ambiental, independentemente do fluxo atual e futuro de bens e serviços apropriados na forma do seu uso (MOTTA, 1997).

Uma das abordagens mais empregadas na valoração econômica ambiental é a do Valor Econômico Total (VET). Esta abordagem procura estrutura de classificação dos diferentes tipos de valores que as pessoas derivam dos bens e serviços ambientais. O valor econômico total de um recurso ambiental compreende a soma dos valores de uso e do valor de existência do recurso ambiental, podendo, este último ser chamado de valor de não uso ${ }^{2}$. Valores de uso compreendem a soma dos valores de uso direto, valores de uso indireto e valores de opção (ORTIZ, 2003).

Um valor de uso direto de um recurso ambiental é aquele derivado da utilização ou consumo direto de um recurso, sendo que o mesmo recurso ambiental pode ter vários usos distintos e, dessa forma, ter vários valores de uso direto. Valores de uso indireto são aqueles advindo das funções ecológicas do recurso ambiental ou aqueles derivados de uso ex-situ ao ambiente do recurso. Valores de opção se relacionam a quantia que os indivíduos estariam dispostos a pagar/receber para manter o recurso ambiental para uso 
futuro. Isto é, não há uso, direto ou indireto, no presente, mas poderá haver o uso no futuro. Em outras palavras, o valor de opção é a disposição a pagar de um indivíduo pela opção de usar ou não um recurso no futuro. O valor de existência ou valor de não-uso de um recurso ambiental está relacionado a satisfação pessoal em saber que o objeto está lá, sem que o indivíduo tenha vantagem direta ou indireta desta presença. Nesse sentido, é distinto do valor de uso, que representa o valor que as pessoas obtêm a partir do uso do objeto.

Em resumo, "o valor econômico total é a soma de todos os seus valores de uso direto e indireto mais o seu valor de opção e o seu valor de existência" (ORTIZ, 2003). Ressalta que "se deve tomar o cuidado de não adicionar valores mais de uma vez ou, ainda, não somar valores que não seriam possíveis se outro uso do recurso tiver sido considerado na valoração econômica" (ORTIZ, 2003).

Utiliza-se também na literatura a expressão Valor Econômico do Recurso Ambiental - VERA com o mesmo intuito do Valor Econômico Total - VET. Assim, uma expressão para o VERA, descrita em Motta, (1997) é $V E R A=(V U D+V U I+V O)+V E$, onde VERA: Valor Econômico do Recurso Ambiental; VUD: Valor de Uso Direto; VUI: Valor de Uso Indireto; VO: Valor de Opção; e VE: Valor de Existência.

A Valoração Econômica Ambiental baseia-se nos axiomas da Teoria do Bem-estar que permite que se calcule o excedente do consumidor, o excedente do produtor e o excedente total ${ }^{3}$, resultante da alocação de um recurso ou bem em um mercado de competição perfeita. Para que se possa estimar o excedente do consumidor total, faz-se necessário estimar a curva de disposição a pagar marginal dos usuários dos bens ambientais que é equivalente à disposição a receber compensação. Essas curvas são estimadas utilizando os métodos de valoração, diretos ou indiretos, cuja escolha depende de vários fatores (contexto, bem de não mercado, custos, conhecimentos etc.) (CASTRO et al., 2010).

Os principais métodos de valoração econômica ambiental são classificados de várias maneiras por diferentes autores. Conforme Ortiz (2003) "estes geralmente são ditos diretos ou indiretos, observados ou hipotéticos ou, ainda baseados em função de produção ou função de demanda ${ }^{4 \prime}$. Os métodos diretos usam a disposição a pagar (DAP) ou a disposição a receber (DAR) derivadas das pesquisas diretas baseadas em mercados hipotéticos e estão assentados nos pressupostos da preferência declarada, ou seja, procuram inferir as preferências individuais por bens ou serviços ambientais a partir de perguntas feitas diretamente às pessoas, e estas estabelecem suas preferências em relação ao recurso ambiental.

Por sua vez, os métodos indiretos usam preços de mercado ou proxies para os bens e serviços ambientais de mercado e baseiam-se nos pressupostos da preferência revelada, ou seja, os métodos de valoração indiretos são aqueles que, inferem o valor econômico de um recurso ambiental a partir da observação do comportamento dos indivíduos em mercados relacionados com o ativo ambiental, sejam estes bens complementares ao consumo do recurso ambiental ou de bens substitutos ao mesmo (CASTRO et al., 2010; ORTIZ, 2003).

\footnotetext{
${ }^{3}$ Pindyck (2010); Varian (2012); Vasconcellos et al. (2011).

${ }^{4}$ Para maiores detalhes dos métodos de valoração econômica dos recursos naturais ver Motta (1997).
} 
Neste estudo, é utilizado um método direto - o Método de Valoração Contingente (MVC) - que é utilizada para estimar o valor de uso direto, valor de uso indireto, valor de opção e valor de não uso (existência) da comunidade local baseada nos bens ambientais derivados dos manguezais, sobretudo, o principal produto, o caranguejo. No método de valoração contingente são criados mercados hipotéticos do recurso ambiental - ou cenários envolvendo mudanças no recurso - e as pessoas expressam suas preferências através da DAP ou da DAR para evitar a alteração na qualidade ou quantidade do recurso ambiental.

A grande vantagem do método de valoração contingente sobre os demais métodos de valoração econômica ambiental, segundo Ortiz (2003) “é que esse método é o único que permite a estimação de valores de existência". Segundo Ortiz (2003), isso porque não observamos o comportamento dos indivíduos em mercado correlato ao do recurso ambiental; pelo contrário: cria-se um cenário hipotético em que os indivíduos expressam suas preferências, e esse cenário não precisa estar relacionado ao uso ou ao conhecimento prévio do recurso ambiental pelos indivíduos. Desta forma, Ortiz (2003) "podemos obter as preferências individuais sobre recursos ambientais que nunca foram ou serão utilizados pelas pessoas, o que caracteriza o valor de não uso ou valor de existência ${ }^{5 \prime}$.

\section{Método de Valoração Contingente (MVC)}

O interesse pelo método da valoração contingente tem crescido bastante ao longo das últimas duas décadas. Dentre tantos motivos, destaca-se o próprio aperfeiçoamento das pesquisas de opinião e, principalmente, o fato de ser a única técnica com potencial de captar o valor de existência (MOTTA, 1997). O método da valoração de contingente consiste na aplicação de questionários onde, além de informações socioeconômicas, os entrevistados respondem o quanto estão dispostos a pagar (DAP) por alguma mudança na provisão de um bem ou serviço ou prevenir uma mudança' e/ou quanto estão dispostos a receber (DAR) compensação para abandonar ou tolerar uma mudança.

No mercado contingente, é feita a descrição do bem sendo proposto hipoteticamente, o contexto institucional em que o bem está inserido e como será provido, e a forma como é financiado. Uma vez obtido os dados de disposição a pagar, calcula-se o DAP ou DAR para a amostra que servirá de base na estimação da disposição a pagar da população.

Conforme Motta (1997), considerando as medidas de DAP e $D A R^{6}$, relativas a mudanças de um recurso ambiental $(\mathrm{Q})$, que mantém o nível de utilidade inicial do consumidor, nota-se: $U\left(Q_{0}, Y_{0}\right)=$ $U\left(Q^{+}, Q^{-}\right)=U\left(Q^{+}, Y^{-}\right)=U\left(Q^{-}, Y+D A R\right)=U\left(Q^{+}, Y-D A P\right)$, onde: $U=$ função utilidade; $Q_{0}=$ disponibilidade de um recurso natural inicial; $Y_{0}=$ renda inicial; $Q-=$ disponibilidade de um recurso natural menor; $\mathrm{Y}_{+}=$renda maior; $\mathrm{Q}_{+}=$disponibilidade de um recurso natural maior; $\mathrm{Y}-=$ renda menor; $\mathrm{Y}=$ renda; DAR = Disposição a receber; e DAP = Disposição a pagar.

\footnotetext{
${ }^{5} \mathrm{O}$ valor de existência não se revela por complementaridade ou substituição a um bem privado, uma vez que o valor de existência não está associado ao uso do recurso e, sim, a valores com base unicamente na satisfação altruísta de garantir a existência do recurso (MOTTA, 1997).

${ }^{6}$ Estimando diretamente as medidas DAR e DAP, o MCV obtém diretamente medidas hicksianas do excedente do consumidor/produtor.
} 
A equação anterior apresenta diferentes pontos com distintas combinações de renda $(Y)$ e provisão de recursos ambientais $(Q)$, que se encontram na mesma curva de indiferença relativa a um determinado nível de utilidade $(U)$. Como a função de utilidade $U$ não é observada diretamente, o método de valoração de contingente estima os valores de DAR e DAP com base em mercados hipotéticos, ou seja, a simulação destes mercados é realizada com pesquisa de campo por meio de questionários que captam do entrevistado suas DAR e DAP em resposta à possíveis alterações na disponibilidade dos recursos ambientais $(Q)$ (MOTTA, 1997).

De acordo com Motta (1997), o MVC é conduzido por meio de dois estágios: Estágio 1: Definição da pesquisa e do questionário. Tem-se: Objeto de valoração: é determinado o recurso ambiental a ser valorado e que parcela de valor econômico está se medindo. Especifica-se com clareza, o bem ou serviço ambiental para o entrevistado e a alteração da disponibilidade do recurso que está sendo questionada, determinando quem utiliza o recurso e quem deve pagar ou ser compensado; A medida da valoração: é decidido qual será a forma de valoração entre a disposição a pagar (DAP), como um pagamento para medir uma variação positiva de disponibilidade, ou a disposição a receber (DAR), como uma compensação por uma variação negativa.

Ainda no Estágio 1, tem-se, Forma de elicitação: é definida a forma a qual o entrevistador perguntará o quanto as pessoas estariam dispostas a pagar ou a receber. Seria de uma forma ou de outra a formulação de perguntas. Um exemplo tradicional do MVC é a forma aberta, onde o questionário apresenta a seguinte questão: 'quanto você está disposto a pagar?'. Assim, esta pergunta produz uma variável contínua de lances e o valor esperado da DAR ou DAP podem ser estimados pela média e com técnicas econométricas de regressão.

Continuando nesse Estágio, visualiza-se: $\mathrm{O}$ instrumento de pagamento: é definido o instrumento de pagamento, ou compensação com que a medida de DAP ou DAR será realizada; A forma da entrevista: é definido como será a aplicação do questionário, onde se recomenda que sejam pessoais e que permitam um controle amostral das entrevistas, além de uma fiel compreensão do questionário e suas respostas; Nível de informação: é determinado o conteúdo das informações contidas no questionário, de forma a passar as transformações ocorridas no recurso ambiental em valoração. Podem ser lidas pelo entrevistador, mostrado através de fotos ou ilustrado.

Por fim, encerrando-se o estágio 1, têm-se: Os lances iniciais: determinar um intervalo de valores monetários que variem do máximo ao mínimo da DAR ou DAP; e Pesquisas focais: para estabelecer pontos extremos de máximo e mínimo da demanda, podem-se realizar pequenas pesquisas de elicitação abertas, por meio de grupos focais são importantes. O Desenho da amostra define a amostra, a qual deve obedecer a procedimentos estatísticos padrões que garantam sua representatividade.

Parte-se para o Estágio 2: Cálculo e estimação. Neste, tem-se: Pesquisa-piloto e pesquisa final: antes da pesquisa final é realizada uma pesquisa piloto, com o objetivo de testar o questionário desenvolvido. A pesquisa final por sua vez é feita, com vista à obtenção de um procedimento comum e uniforme de entrevistas, com uma conferência dos questionários e controle da amostra. 
Além disso, Cálculo da medida monetária: no caso de questionários de elicitação aberta, o qual será utilizado neste trabalho, o valor médio é obtido diretamente com a aplicação direta de técnicas econométricas de regressão para validar o resultado. Uma curva de lances livres pode ser estimada para determinar as respostas de DAP, correlacionando em função Visitas $(Q)$, renda $(Y)$, fatores sociais com educação $(S)$ e outras variáveis explicativas $(X)$.

Assim como, um parâmetro da qualidade ambiental do lugar $(E)$ também pode ser incluído. Propõese a fórmula $D A P_{i}=f\left(Q_{i j}, Y_{i}, S_{i}, X_{i}, E_{j}\right)$. Não existe uma forma teórica correta para a função (2.2.2). Esta função permite estimar mudanças na média DAP originárias de variações em $E$, ou seja, $\partial D A P_{i} / \partial E_{j}$. Por fim, encerrando-se o Estágio 2, visualiza-se A agregação dos resultados: a partir da média (ou mediana) da DAP ou DAR, o valor econômico total é estimado multiplicando esta média pela população afetada pela alteração de disponibilidade.

\section{METODOLOGIA}

\section{Área de estudo da pesquisa}

O estudo foi realizado no município de São Caetano de Odivelas, Mesorregião Nordeste do estado do Pará e possui um pouco mais de 16 mil habitantes distribuídos nas 41 comunidades em sua sede, dentro de uma área de $724,10 \mathrm{~km}^{2}$. A economia dessa população é baseada no extrativismo animal como a pesca tradicional, coleta de caranguejo, no extrativismo vegetal dos manguezais, e na agricultura (PICANÇO, 2012).

Dentre os rios encontrados no Município de São Caetano de Odivelas no sentido sul-norte, desaguando no Oceano Atlântico têm-se o Rio Mojuim, o mais importante porque forma toda a bacia hidrográfica após entrar em território de São Caetano de Odivelas, a sudeste, segue em direção norte e deságua no Atlântico, banhando antes o Distrito de Perseverança, os povoados de Porto Grande e Guarajuba, e a sede municipal, no município de São João da Ponta. Destaca-se ainda o Rio Maruim Panema, que banha a Vila de São João dos Ramos, e o Rio Mocajuba que banha a Vila de São Miguel, e servem de limite natural, a leste, com o município de Curuçá; e o Rio Barreta, a noroeste, que verte para o Oceano Atlântico e serve de limite com o município de Vigia.

A vegetação encontrada na região é constituída de: vegetação de restinga, vegetação de mangue, vegetação de campo natural inundável e vegetação secundária (PICANÇO, 2012). A vegetação de mangue é tipicamente composta por planícies de maré sob influência de água salobra, ou planícies fluviomarinhas, com fisiografia ideal para a formação dessa vegetação, pois constituem áreas pantanosas ou lamacentas, cobertas pelas águas durante as marés enchentes e descobertas nas marés vazantes, recebendo também águas das drenagens fluvial e subterrânea (PROST et al., 2001). O levantamento e coleta de dados foram realizados Ilha São Miguel a $00^{\circ} 43^{\prime} 49,1^{\prime \prime}$ S e $47^{\circ} 57^{\prime} 59.9^{\prime \prime}$ W, conforme ilustração proposta na figura 1.

Na figura 1 está o registro visual do ponto de encontro dos coletores, que também é um símbolo da roda de conversa no fim de tarde dos comunitários. Ressalta-se que, na época da realização da pesquisa, 
estava sendo contruída a rampa do trapiche da Vila São Miguel, respectivamente no local exato da Figura 1 (b), o que facilitaria o transporte de carga e pessoas do vilarejo.
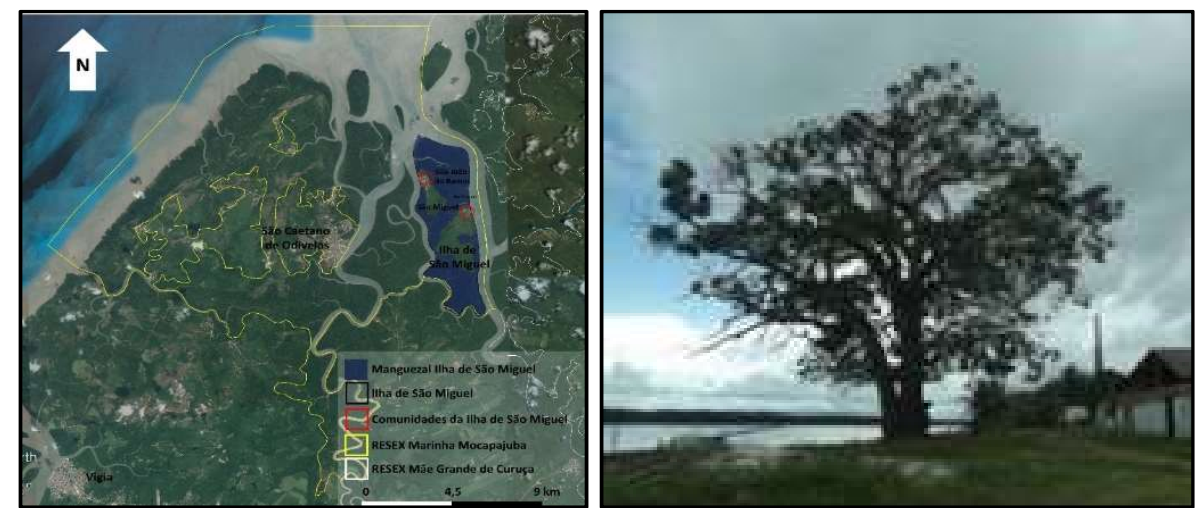

Figura 1: Localização geográfica da Vila São Miguel no Município de São Caetano de Odivelas (PA).

\section{Procedimentos Metodológicos da Pesquisa}

A pesquisa foi executada em três etapas: visita de reconhecimento; minicurso sobre noções de valoração; e aplicação dos questionários. Na primeira etapa, fez-se uma visita de reconhecimento da área de estudo. Esta etapa teve como objetivo delimitar e se conhecer em detalhes a área de estudo, particularmente a comunidade tradicional localizada na proximidade do manguezal, além de troca de informações com informantes-chaves, como por exemplo, as lideranças comunitárias da Vila São João do Ramos e da Vila São Miguel (local da pesquisas) com o intuito de determinar o número de famílias existentes em cada comunidade, as atividades extrativistas realizadas no manguezal e sua forma de captação, além de informações acerca do uso de outros recursos proveniente do mangue.

Na segunda etapa, foi realizado um minicurso intitulado 'Valoração Econômica dos Recursos do Manguezal', cujo foco era de apresentar, de forma clara e concisa, o objetivo da valoração econômica do recurso além de 'aguçar' nos comunitários os valores consultivos da Disposição a Receber (DAR) dos recursos naturais fornecidos pelo manguezal, sobretudo o caranguejo, principal produto de coleta do manguezal e, fonte de subsistência e comércio naquela comunidade.

Na terceira etapa, ocorreu a aplicação dos questionários ${ }^{7}:$ O questionário teve como objetivo coletar dados e informações sobre o perfil socioeconômico e demográfico dos comunitários, as características de suas atividades extrativistas, a identificação dos tipos de usos e produtos extraídos do manguezal, além de identificar os valores atribuídos ao uso direto, indireto, opção e existência - todos consultivos - dos recursos dos manguezais.

O questionário possui um total 43 questões, divididas em três partes: Parte l: composta de dezesseis questões visando a caracterização dos comunitários/usuários do manguezal - condições sociais, econômicas e demográficas, além de identificar as atividades e usos dos manguezais pelas comunidades, e os produtos obtidos dele; Parte II: composta de 19 questões com foco a identificação dos tipos recursos e de uso (diretos

\footnotetext{
${ }^{7}$ Essa pesquisa adotou um modelo não-probabilístico por conveniência - aquela em que o pesquisador 'seleciona' membros da população mais acessíveis.
} 
e indiretos) e de não-uso (opção e existência) do manguezal. Parte III: composta de 6 questões consiste da descrição do mercado hipotético dos usos consultivos diretos, indiretos, opção e existência do manguezal, do instrumento de pagamento, e da questão que procurou elicitar a disposição a receber (DAR) compensação para deixar derivar valores de usos dos recursos do manguezal, relacionados à coleta do caranguejo.

\section{Caracterização do Grupo de Entrevistados}

A comunidade é formada por aproximadamente 83 famílias e, a entrevista contou com uma amostra de $n=33$ indivíduos, representando um total de 28 famílias. A especificação dos entrevistados por gênero é de, aproximadamente, $61 \%$ dos entrevistados serem do sexo masculino e, $39 \%$ do sexo feminino. No quesito idade, o entrevistado mais novo possuía 17 anos, sendo apenas 1 do total e o mais idoso com 63, estando 2 entrevistados nessa faixa etária.

O estado civil dos entrevistados observou-se ser o grupo de solteiros e união estável mais eminente entre os entrevistados, apresentado ambos praticamente a mesma incidência, de aproximadamente $42 \%$ e $40 \%$, respectivamente, ao passo de os grupos de casados e divorciados, apresentaram a mesma frequência de $3 \%$.

Na distribuição da variável escolaridade, as maiores frequências foram apresentadas para os grupos ensino médio completo acompanhado do ensino fundamental incompleto, com aproximadamente $40 \% \mathrm{e}$ $31 \%$ de incidência. Já o grupo de ensino fundamental completo e o de curso técnico apresentaram menores incidências, com $2 \%$ ambas. Quanto ao questionamento sobre o prosseguimento nos estudos, a grande maioria dos entrevistados, aproximadamente $73 \%$ responderam não, ressaltando-se que não foram questionadas as possíveis condicionantes desta última resposta.

No quesito tempo de residência na comunidade, apresentou-se como menor resultado o de 11 anos, ao passo que o de maior resultado de 62 anos, representando aproximadamente $4 \%$ e $8 \%$ da amostra. Quando questionado sobre quais os antepassados habitaram na comunidade, a grande maioria identificou seus avós, representando $85 \%$ da amostra.

Quanto ao questionamento acerca da atividade principal, 64\% responderam ser coletor de caranguejo. Ressalta-se que a porcentagem dos respondentes negativos (36\%), não descarta toda e qualquer relação com a atividade de coleta do caranguejo no manguezal, seja direta ou indireta. Quanto a idade que iniciou sua atividade principal - sendo está de $64 \%$ para a coleta do caranguejo - a idade mínima apresentado foi de 8 anos e a máxima de 25 anos. Ressalta-se que, a grande maioria dos entrevistados (79\%) respondeu exercer alguma atividade complementar 'remunerada' na comunidade.

Ao ser questionado sobre o fato de ser ou não o principal mantenedor da família, as respostas ficaram equilibradas, aproximadamente metade para ambas. Quanto ao fato de ser o único mantenedor da família, mais de 60\% responderem não. Na descrição estatística demográfica dos entrevistados, o número de residentes, apresentou uma média de 4,85, com desvio de 1,97 e mínimo e máximo de 2 e 9 indivíduos, aproximadamente. Já, a descrição estatística socioeconômica dos entrevistados, quanto a renda familiar mensal é. 
Tabela 1: Descrição Estatística da Renda Mensal das Famílias.

\begin{tabular}{|c|c|c|c|c|c|}
\hline Sumário Descritivo & Observações & Média & Desvio Padrão & Mínimo & Máximo \\
\hline Renda da Venda de Caranguejo & $27^{*}$ & 596.6667 & 342.40 & 0 & $1.500,00$ \\
\hline Renda de Atividade Complementar & 33 & 396.6667 & 461.69 & 0 & $1.600,00$ \\
\hline Renda Familiar Total & 33 & $1.176,667$ & 618,31 & 160,00 & $2.682,00$ \\
\hline
\end{tabular}

A renda proveniente da venda do caranguejo, apresentou média de $\mathrm{R} \$ 596,66$, desvio padrão de $\mathrm{R} \$ 342,40$, mínimo de zero e o máximo de $\mathrm{R} \$ 1.500,00$. O rendimento proveniente de atividade complementar, apresentou média de $\mathrm{R} \$ 396,66$, desvio padrão de $\mathrm{R} \$ 461,69$, mínimo de rendimento igual a zero e máximo de $R \$ 1.600,00$. A renda familiar total dos entrevistados, apresentou média de $R \$ 1.117,67$, desvio padrão de $R \$ 618,32$ e mínimo de $R \$ 160,00$ máximo de $R \$ 2.682,00$.

Ainda na caracterização socioeconômica dos comunitários, foi perguntado sobre o recebimento de transferências governamentais proveniente de aposentadorias/pensões nas famílias, sendo, portanto, a frequências de não aposentados superior à de aposentados, com valor iguais a $75 \%$ e $25 \%$, respectivamente. Quanto ao recebimento na família de transferências condicionadas provenientes do Programa Bolsa Família (PBF), a frequência de recebimento foi superior ao não recebimento, apresentando incidência de 63\% e 37\%. Quanto ao recebimento na família de transferências condicionadas provenientes do Seguro Defeso, 100\% dos entrevistados responderam não receber este tipo de transferência na família.

\section{RESULTADOS}

\section{Atividades, Produtos e Usos do Manguezal com Base no Valor de Uso Direto (VUD) e Valor de Uso Indireto (VUI)}

A importância da identificação das atividades, produtos e tipos de uso dos bens ambientais oriundos do ecossistema manguezal é de suma importância para a definição dos valores que compõe o VERA. A descrição das atividades, produtos e tipos de uso estão descritos nas subseções. Na tabela 2, encontra-se a distribuição de frequência do uso direto da coleta de mariscos do manguezal, como também a distribuição por tipo de produto.

Tabela 2: Distribuição de Frequência do Uso Direto da Coleta de Mariscos.

\begin{tabular}{|c|c|c|c|c|c|c|c|c|}
\hline \multirow{2}{*}{$\begin{array}{l}\text { Coletor de Mariscos / } \\
\text { Tipo de produto }\end{array}$} & \multicolumn{2}{|c|}{ Coletor } & \multicolumn{2}{|c|}{ Caranguejo } & \multicolumn{2}{|c|}{ Siri } & \multicolumn{2}{|c|}{ Ostras } \\
\hline & (fi)* & (fri)\%** & $(f i)^{*}$ & (fri)\%** & $(f i)^{*}$ & (fri)\%** & $(f i)^{*}$ & (fri)\%** \\
\hline Sim & 29 & 87.88 & 31 & 93.94 & 14 & 42.42 & 4 & 12.12 \\
\hline Não & 4 & 12.12 & 2 & 6.06 & 19 & 57.58 & 29 & 87.88 \\
\hline Total & 33 & 100 & 33 & 100 & 33 & 100 & 33 & 100 \\
\hline Tipo de produto & \multicolumn{2}{|c|}{ Sapequara } & \multicolumn{2}{|c|}{ Mexilhão } & \multicolumn{2}{|c|}{ Camarão } & \multicolumn{2}{|c|}{ Turu } \\
\hline Sim & 7 & 21.21 & 7 & 21.21 & 14 & 42.42 & 22 & 66.67 \\
\hline Não & 26 & 78.79 & 26 & 78.79 & 19 & 57.58 & 11 & 33.33 \\
\hline Total & 33 & 100 & 33 & 100 & 33 & 100 & 33 & 100 \\
\hline
\end{tabular}

A tabela 2 informa que do total dos entrevistados, aproximadamente $88 \%$ fazem uso direto dos produtos do manguezal, através da coleta de mariscos. Discriminando por tipo de produto: caranguejo, siri, ostras, sapequara, mexilhão, camarão, turu, a coleta destes, com base ainda na tabela 2, é de, aproximadamente, $94 \%, 43 \%, 12 \%, 22 \%, 22 \%, 43 \%, 67 \%$, respectivamente, dentre o total de produtos coletados junto ao manguezal. Ou seja, o principal produto coletado no manguezal, de forma direta é o 
caranguejo. Quanto à destinação final da produção oriunda da coleta de mariscos, a tabela 3 apresenta a distribuição que lhe foi proposta.

Tabela 3: Destinação Final do Produto da Coleta.

\begin{tabular}{|c|c|c|c|}
\hline Destino da Produção & (fi) & (fri) \% & (Fri) \% \\
\hline Venda/Troca & 6 & 19.35 & 19.35 \\
\hline Consumo & 2 & 3.225 & 25.81 \\
\hline Consumo-Venda/Troca & 4 & 12.9 & 38.71 \\
\hline Venda/Troca - Consumo & 19 & 61.29 & 100 \\
\hline Uso Não Identificado & 2 & 3.225 & 100 \\
\hline Total & 33 & 100 & \\
\hline
\end{tabular}

Tomando por base a tabela acima, aproximadamente $20 \%$ da produção é destinado à venda/troca, um pouco mais de $3 \%$ destinado ao consumo da família; $13 \%$ ao consumo e venda/troca (neste caso a venda/troca se dá depois de extraído o quantitativo necessário para o consumo); $62 \%$ destinado a venda/troca e consumo (neste caso o consumo se dá depois de extraído o quantitativo necessário para a venda/troca) e; pouco mais de 3\% não identificou o tipo de destinação dado à produção. Enfatiza-se que, a destinação do produto voltada para a 'Venda/Troca-Consumo e Venda/Troca é mais significativa, responsável por, aproximadamente $82 \%$ da destinação final do produto.

Quanto às atividades complementares ligadas ao uso direto do manguezal, foram identificadas como as mais intensas: a pesca, a extração de madeira e a coleta de aves, cabendo fazer as seguintes ressalvas: Pesca: mais de $90 \%$ dos entrevistados exerce a pesca no estuário. Discriminando pela forma que exercem a pesca, aproximadamente $52 \%, 70 \%$ e $34 \%$ afirmaram utilizar a rede, linha e espinhel, respectivamente, em suas atividades de pesca.

Pouco mais de $3 \%$, afirma ser a venda/troca o destino final dos produtos pesqueiros; $52 \%$ ser apenas o consumo; $22 \%$ identificaram o consumo e a venda/troca (neste caso a venda/troca se dá depois de extraído o quantitativo necessário para o consumo); $16 \%$ destinado à venda/troca e o consumo (neste caso o consumo se dá depois de extraído o quantitativo necessário para a venda/troca) e; pouco mais de $3 \%$ não identificou o tipo de destinação dado à produção. Enfatiza-se que, a destinação do produto voltada para o consumo é mais significativa, apresentando-se superior a $50 \%$ da distribuição total.

A segunda ressalva é Extração de Madeira: do total dos entrevistados, mais de $90 \%$ fazem uso direto da extração de madeiras do manguezal. Discriminando por utilidade dada aquele produto extraído: lenha, curral, cercado, jirau, chiqueiro, suporte do laço e inseticida, com base ainda na tabela acima, é de, aproximadamente, 33\%, 9\%, 9\%, 9\%, 9\%, 0\%, 3\% e 12\%, respectivamente. Ou seja, a principal utilidade dada às madeiras extraída no manguezal é o uso desta como inseticida. Ressalta-se que nenhum dos entrevistados informou da utilização das madeiras para uso em chiqueiros. 45\%, afirmou ser o consumo (ou seja, para uso pessoal) o destino das madeiras coletadas; $33 \%$ disse não fazer uso para nenhum fim e; $22 \%$ não identificaram o uso. Enfatiza-se que, a destinação do produto voltada para o consumo é mais significativa, apresentando-se a maior frequência na distribuição.

A terceira e última ressalva é a Coleta de Aves: $48 \%$, afirmou fazer coleta de aves no manguezal 33\%. Discriminando por tipo/espécie, os entrevistados afirmaram coletar (ou já ter coletado): Guará em 28\%; Pato 
do Mato em 28\%; Maçarico 22\%; Taquiri em 16\% e; Gavião em 6\%. Ressalta-se que o Guará e Pato do Mato são os tipos/espécies de aves mais comuns coletadas no manguezal, apresentando assim a maior frequência na distribuição. 48\%, afirmou ser o consumo (ou seja, para uso pessoal) o destino final das aves coletadas; $8 \%$ identificou ser o consumo e venda/troca (aqui o uso particular antecede a venda/troca do produto); $44 \%$ não identificaram o uso. Enfatiza-se que, a destinação do produto voltada para o consumo é mais significativa, apresentando-se a maior frequência na distribuição.

Alguns pontos importantes, ainda devem ser ressaltados quando se verifica a relação da sociedade local com a natureza na comunidade: alguns moradores fazem cultivo de plantas e ervas nos seus quintais, para fins ornamentais e medicinais; além do cultivo das plantas e ervas, alguns moradores fazem uso do roçado; percebeu-se também a criação de aves, seja para consumo e/ou venda/troca, tais como galinhas, patos, e aves de canto, passarinhos diversos e; Verificou-se também a produção de artesanatos para diversos fins, tais como a ornamentação das residências, a venda aos turistas, e até no auxílio da principal atividade desenvolvida no manguezal - a coleta do caranguejo, com a produção das coifas (cesto de carregar o caranguejo do mangue).

\section{Atividades, Produtos e Usos do Manguezal com Base no Valor de Opção (VO) e Valor de Existência (VE)}

A fim de identificar os valores de não uso - de opção (VO) e existência (VE) dos recursos ambientais do manguezal, iniciou-se com a noção de manejo por parte dos comunitários, identificada nas entrevistas. $\mathrm{Na}$ tabela 4, abaixo, encontra-se a distribuição de frequência do valor de opção e existência do manejo no uso direto na coleta de mariscos, discriminada ainda pelo intuito daquele ato.

Tabela 4: Distribuição de Frequência do Manejo dos Mariscos por Intuito do Ato.

\begin{tabular}{|c|c|c|c|c|c|c|c|c|}
\hline \multirow{2}{*}{ Manejo dos Mariscos / Intuito do Ato } & \multicolumn{2}{|c|}{ Manejo Marisco } & \multicolumn{2}{|c|}{ Garantia da Produção } & \multicolumn{3}{|c|}{ Escassez } & Geração Futura \\
\cline { 2 - 9 } & $\left(\mathbf{f i}^{*}\right.$ & (fri)\%** & (fi)* & (fri)\%** & (fi)* & (fri)\%** & (fi)* & (fri)\%** \\
\hline Sim & 31 & 93.94 & 25 & 75.76 & 8 & 24.24 & 6 & 18.18 \\
\hline Não & 2 & 6.06 & 8 & 24.24 & 25 & 75.76 & 27 & 81.82 \\
\hline Total & 33 & 100 & 33 & 100 & 33 & 100 & 33 & 100 \\
\hline
\end{tabular}

A tabela acima informa que do total dos entrevistados, mais de $93 \%$ afirmam realizar, de alguma forma, o manejo dos mariscos do manguezal. Discriminando por finalidade daquele ato, aproximadamente, $76 \%$ diz ser a garantia da produção do futuro; $25 \%$ a percepção da escassez (no presente, considerando o histórico de períodos anteriores) e; apenas $19 \%$ considera a geração futura, como finalidade da realização do manejo na coleta.

Em outras palavras, a principal explicação dada ao manejo de mariscos do manguezal está no fato da garantia da produtividade no longo prazo, ao passo que, a preocupação com a sustentabilidade focada na utilização do recurso pela geração futuro foi a menos destacada pelos entrevistados. Quanto à importância da difusão do saber local, a tabela 5 apresenta a distribuição de frequência, discriminado pelo intuito de ser praticar o ato na comunidade. 
Tabela 5: Distribuição de Frequência da Importância da Difusão do Saber Local

\begin{tabular}{|c|c|c|c|c|c|c|c|c|c|c|}
\hline \multirow{2}{*}{ Saber Local / Importância da Difusão } & \multicolumn{2}{|c|}{ Difusão do Conhecimento } & \multicolumn{2}{|c|}{ Manter Tradição } & \multicolumn{2}{|c|}{ Garantia de Consumo } & \multicolumn{2}{|c|}{$\begin{array}{l}\text { Prevenir a } \\
\text { Escassez }\end{array}$} & \multicolumn{2}{|c|}{$\begin{array}{c}\text { Geração } \\
\text { Futura }\end{array}$} \\
\hline & $(f i)^{*}$ & $\begin{array}{c}\text { (fri)\% } \\
* *\end{array}$ & $(f i)^{*}$ & $\begin{array}{l}\text { (fri)\% } \\
* *\end{array}$ & $(f i)^{*}$ & $\begin{array}{c}\text { (fri)\% } \\
* *\end{array}$ & $(f i)^{*}$ & $\begin{array}{c}\text { (fri)\% } \\
* *\end{array}$ & $(f i)^{*}$ & $\begin{array}{c}\text { (fri)\% } \\
* *\end{array}$ \\
\hline Sim & 31 & 93.94 & 14 & 42.42 & 14 & 42.42 & 6 & 18.18 & 14 & 42.42 \\
\hline Não & 2 & 6.06 & 19 & 57.58 & 19 & 57.58 & 27 & 81.82 & 19 & 57.58 \\
\hline Total & 33 & 100 & 33 & 100 & 33 & 100 & 33 & 100 & 33 & 100 \\
\hline
\end{tabular}

A tabela 5 informa que, do total dos entrevistados, mais de $93 \%$ dos entrevistados consideram importante à difusão do saber local entre as gerações. Discriminando pelo objetivo da prática difusora do saber tradicional na comunidade, aproximadamente, 42 \% dizem ser para manter a tradição; $42 \%$ afirmam ser a garantia de consumo da família no futuro; $18 \%$ afirmam pensar como formar de prevenir a escassez do recurso no futuro e; $42 \%$ consideração à reprodução familiar e pensa no futuro da geração futura.

Ressalta-se que, apesar de não estar descrita em termos quantitativos, para quase $100 \%$ dos entrevistados, em suma, todos aqueles parâmetros acima identificados são objetivos comuns necessários e fazem parte da importância da difusão do conhecimento tradicional junto aos membros das famílias e da comunidade como um todo. A descrição das manifestações culturais e religiosas da comunidade estão dispostos na tabela 6, discriminada pelo nome do festejo.

Tabela 6: Distribuição de Frequência das Manifestações Culturais e Religiosas.

\begin{tabular}{|c|c|c|c|c|c|c|c|c|c|c|c|c|c|c|}
\hline \multirow{2}{*}{$\begin{array}{l}\text { Manifestação Cultural } \\
\text { Conhece / Participa }\end{array}$} & \multicolumn{2}{|c|}{ Relação Mangue } & \multicolumn{2}{|c|}{ Festival do Caranguejo } & \multicolumn{2}{|c|}{$\begin{array}{c}\text { Festejo São } \\
\text { Miguel }\end{array}$} & \multicolumn{2}{|c|}{$\begin{array}{c}\text { Festa do São } \\
\text { Pedro }\end{array}$} & \multicolumn{2}{|c|}{ Boitinga } & \multicolumn{2}{|c|}{ Avuado } & \multicolumn{2}{|c|}{ Mutirão } \\
\hline & $\begin{array}{l}(f i) \\
*\end{array}$ & $\begin{array}{c}\text { (fri) \% } \\
* *\end{array}$ & $(f i)^{*}$ & $\begin{array}{c}\text { (fri) } \% \\
* *\end{array}$ & $\begin{array}{c}(f i) \\
*\end{array}$ & $\begin{array}{c}\text { (fri) } \% \\
* *\end{array}$ & $\begin{array}{c}(f i) \\
*\end{array}$ & $\begin{array}{c}(f r i) \% \\
* *\end{array}$ & $\begin{array}{c}\text { (fi) } \\
*\end{array}$ & $\begin{array}{c}\text { (fri) } \\
\% \\
* *\end{array}$ & $\begin{array}{l}\text { (fi) } \\
*\end{array}$ & $\begin{array}{c}\text { (fri) \% } \\
* *\end{array}$ & $\begin{array}{c}\text { (fi) } \\
*\end{array}$ & $\begin{array}{c}\text { (fri)\% } \\
* *\end{array}$ \\
\hline Sim & 24 & 72.73 & 14 & 42.42 & 6 & 18.18 & 14 & 42.42 & 14 & $\begin{array}{c}42.4 \\
2 \\
\end{array}$ & 14 & 42.42 & 14 & 42.42 \\
\hline Não & 9 & 27.27 & 19 & 57.58 & 27 & 81.82 & 19 & 57.58 & 19 & $\begin{array}{c}57.5 \\
8\end{array}$ & 19 & 57.58 & 19 & 57.58 \\
\hline Total & 33 & 100 & 33 & 100 & 33 & 100 & 33 & 100 & 33 & 100 & 33 & 100 & 33 & 100 \\
\hline
\end{tabular}

Das Manifestações Culturais e Religiosas relacionadas, direta ou indiretamente, com o manguezal, a tabela acima informa que aproximadamente $72 \%$ afirmam conhecer e já ter participado de manifestações culturais e religiosas relacionadas, direta ou indiretamente, com o manguezal. Identificando o conhecimento e/ou participação discriminando pelo nome do festejo, aproximadamente, $18 \%$ identificaram o festejo de São Miguel (comunidade vizinha interligada por uma ponte de madeira sobreposta no mangue que corta o vilarejo) e; $42 \%$ identificaram o festival do caranguejo; a Festa de São Pedro; o rito do Boitinga; a manifestação cultural do Avuado e; a realização de mutirão todos realizados na comunidade, respectivamente. Quanto à existência de crenças e mitos relacionadas com o Manguezal, a tabela 7 descreve a distribuição daquela segundo a sua tipologia denominada comunidade.

Tabela 7: Distribuição de Frequência das Crenças e Mitos

\begin{tabular}{|c|c|c|c|c|c|c|c|c|c|c|}
\hline Manifestação Cultural & \multicolumn{2}{|c|}{ Relação Mangue } & \multicolumn{2}{|c|}{ Ataíde } & \multicolumn{2}{c|}{ Ato Benzer } & \multicolumn{2}{c|}{ Matinta } & \multicolumn{2}{c|}{ Visagem } \\
\hline Conhece / Acredita & (fi) & (fri)\%** & (fi) & (fri)\%** & (fi)* $^{*}$ & (fri)\%** & (fi)* & (fri)\%** & (fi)* & (fri)\%** \\
\hline Sim & 28 & 84.85 & 5 & 15.15 & 16 & 48.48 & 4 & 12.12 & 5 & 15.15 \\
\hline Não & 5 & 15.15 & 28 & 84.85 & 17 & 51.52 & 29 & 87.88 & 28 & 84.85 \\
\hline Total & 33 & 100 & 33 & 100 & 33 & 100 & 33 & 100 & 33 & 100 \\
\hline
\end{tabular}


A tabela acima evidencia que, aproximadamente, $85 \%$ das crenças e mitos estão diretamente relacionados ao manguezal. Conforme o tipo, os entrevistados descreveram conhecer em 15\% o Ataíde (ser antropomórfico que ataca os coletores para fins de satisfação sexual com os mesmos); $48 \%$ afirmaram praticar o ato de se benzer antes do adentrar o mangue, como forma de segurança e proteção; $12 \%$ da existência da matinta; e 15\% relataram sobre a existência/presença de visagem. Ressalta-se que, ao se questionar da presença das figuras mitológicas, os entrevistados, em sua totalidade, relataram nunca ter visto pessoalmente, principalmente o Ataíde. Sobre o conhecimento 'empírico' tradicional das funções ecossistêmicas realizadas no mangue, a tabela 8 apresenta a distribuição de frequências das principais funções relatadas pela comunidade.

Tabela 8: Distribuição de frequência sobre as Funções Ecossistêmicas.

\begin{tabular}{|c|c|c|c|c|c|c|c|c|c|c|c|c|}
\hline Funções Ecossistêmicas & \multicolumn{2}{|c|}{ Possui Conhecimento } & \multicolumn{2}{|c|}{ Fauna } & \multicolumn{2}{|c|}{ Peixes (Sardinha) } & \multicolumn{2}{|c|}{ Insetos } & \multicolumn{2}{c|}{ Guaxinim } & \multicolumn{2}{c|}{ Formiga } \\
\hline Conhece / Participa & $\begin{array}{c}\text { (fi) } \\
*\end{array}$ & $\begin{array}{c}\text { (fri)\% } \\
* *\end{array}$ & $\begin{array}{c}\text { (fi) } \\
*\end{array}$ & $\begin{array}{c}\text { (fri)\% } \\
* *\end{array}$ & $\begin{array}{c}\text { (fi) } \\
*\end{array}$ & $\begin{array}{c}\text { (fri)\% } \\
* *\end{array}$ & $\begin{array}{c}\text { (fi) } \\
*\end{array}$ & $\begin{array}{c}\text { (fri)\% } \\
* *\end{array}$ & $\begin{array}{c}\text { (fi) } \\
*\end{array}$ & $\begin{array}{c}\text { (fri)\% } \\
* *\end{array}$ & $\begin{array}{c}\text { (fi) } \\
*\end{array}$ & $\begin{array}{c}\text { (fri)\% } \\
* *\end{array}$ \\
\hline Sim & 33 & 100 & 11 & 33.33 & 27 & 81.82 & 20 & 60.61 & 26 & 78.79 & 9 & 27.27 \\
\hline Não & 0 & 0 & 22 & 66.67 & 6 & 18.18 & 13 & 39.39 & 7 & 21.21 & 24 & 72.73 \\
\hline Total & 33 & 100 & 33 & 100 & 33 & 100 & 33 & 100 & 33 & 100 & 33 & 100 \\
\hline
\end{tabular}

Em sua totalidade, $100 \%$ dos entrevistados relataram conhecer/saber (aqui é o saber empírico local) de alguma função desenvolvida pelo ecossistema do manguezal, podendo essa estar, diretamente ou indiretamente relacionada ao caranguejo. Descriminando as principais funções ecossistêmicas descritas pelos entrevistados, aproximadamente, $33 \%$ dos entrevistados identificaram a fauna, em sua função dispersora de sementes; $82 \%$ relataram sobre a presença de sardinha.

Essa presença como forma de bioindicador da presença de cardumes de outras espécies de peixes; $60 \%$ identificaram através dos insetos (maruim, pium e mosquitos em gerais como o carapanã, mutuca e mosca) como transmissores de doenças tais como malária, dengue e etc.; $78 \%$ relataram o guaxinim como predador maior do caranguejo (houve relatos de problemas causado pelo animal na hora da coleta) e; 27 afirmaram saber da função da formiga como alimento de outras espécies, proteção da planta e também predadoras de outras espécies da fauna e flora.

Ressalta-se que além daquelas funções acima identificadas pelos comunitários, houve relatos da possibilidade da existência de demais funções, das quais os mesmos não souberam discriminar no ato da entrevista. Foi questionado sobre a introdução de novos conhecimentos, comprovados cientificamente, seja na ampliação do saber empírico ou de conhecimento puramente novo adquirido a partir da oficina ${ }^{8}$ realizada in loco. Do total de entrevistados, a maioria (90\%) afirmou ter adquirido/ampliado o seu conhecimento acerca das funções ecossistêmicas do mangue.

Considerando as principais funções ecossistêmicas identificadas empiricamente pelos comunitários, percebeu-se que para todas as funções empíricas houve no mínimo um conhecimento novo adquirido ou

\footnotetext{
8 A oficina intitulada 'Valoração Econômica dos Recursos do Manguezal' realizada na Escola da comunidade de São Miguel em São Caetano de Odivelas. Durante a oficina foi realizada exposição de banners com as funções ecossistêmicas do manguezal (fauna, flora, etnobotânica, antroplogia etc.) e a apresentação dos princípios, conceitos e tendências econômicas sobre a valoração econômica do ecossistema manguezal. Ambas as apresentações tinham como foco o melhor entendimento das funções e da valoração do manguezal nos mais diversos usos, visando uma melhor resposta quanto às disposições a pagar e receber dos comunitários.
} 
ampliado relatado pelos entrevistados da seguinte maneira: 39\% relataram novo entendimento/conhecimento na função da formiga como alimento de outras espécies, proteção da planta e também predadoras de outras espécies da fauna e flora; 52\% dos entrevistados identificaram a fauna (aves), em sua função dispersora de sementes; 39\% identificaram a função dos insetos (maruim, pium e mosquitos em gerais como o carapanã, mutuca e mosca, como transmissores de doenças tais como malária, dengue e etc.; e 52\% relataram sobre o papel do caranguejo na aeração do solo.

\section{DISCUSSÃO}

Após a identificação dos tipos e valores/não valores que contemplam o VERA (Valor Econômico dos Recursos Ambientais), metodologicamente foi proposto extrair, de forma consultiva, uma DAR (Disposição a Receber) para cada componente do VERA - Valor de uso direto; indireto; opção e existência - todos relacionados ao caranguejo.

\section{Disposição à Receber Compensação pela Perda do Acesso e Uso do Manguezal}

Do total de 33 entrevistados, 100\% responderam um valor a DAR com relação aos valores de uso direto e indireto do manguezal; com relação ao valor da DAR do não uso e valor de opção apenas 1 entrevistado (3,13\%) não soube/ausentou de opinar. Já para o valor da DAR do não uso e valor de existência 4 entrevistados (12,50\%) não soube/ausentou de opinar.

Na opinião dos não respondentes, aqueles argumentaram que refeririam não opinar/responder por ter achado que os benefícios derivados dos produtos extraídos do manguezal são maiores do que o valor monetário que eles poderiam indicador na consulta da DAR. Na tabela 9, encontra-se o sumário descritivo para a Disposição a Receber Total, calculada a partir do somatório individuais das DARs dos quatros grupos de valores de uso (direto e indireto) e de não uso (opção e existência).

Tabela 9: Sumário Descritivo para a DAR Individual Total Calculada

\begin{tabular}{|c|c|c|c|c|c|}
\hline Sumário Descritivo & Observações & Média & Desvio Padrão & Mínimo & Máximo \\
\hline Renda Familiar Total & 33 & $4.463,36$ & $3.114,18$ & 1.280 & 14.500 \\
\hline
\end{tabular}

Com base na tabela acima, percebe-se que a média da DAR Individual Total estimada foi de $\mathrm{R} \$ 4.463,36$, com desvio de $\mathrm{R} \$ 3.114,18$, mínimo de $\mathrm{R} \$ 1.280,00$ e máximo de $\mathrm{R} \$ 14.500,00$ por mês. Pretendendo estimar apenas o excedente do consumidor total gerada a partir dos produtos extraídos dos manguezais, focando-se nos valores derivados a partir do uso direto, indireto, opção e existência do manguezal obtidos pela comunidade local encontra-se, na figura 2, a Disposição a Receber Marginal (DARMa) estimada dos entrevistados.

A área abaixo da curva de disposição a receber marginal corresponde à disposição a receber total $(D A R)$ da amostra. A DAR total/mensal é calculada da seguinte maneira: $D A R($ total $/$ mensal $)=$ $\sum D A R$ (individual/mensal). O valor da DARtotal ${ }^{9}$ mensal estimado para os 33 respondentes foi de

\footnotetext{
${ }^{9}$ A DARtotal foi estimada levando em consideração todos os componentes do VERA - valores de usos diretos, indiretos e de não uso (existência) e suas respectivas disposições a receber individuais, ou seja, a DARtotal é o somatório das DARs individuais de cada valor do VERA.
} 
$\mathrm{R} \$ 147,291.00$, enquanto o valor médio da DAR (DARMe-mensal), obtida: DARme(mensal) $=$ $\frac{D A R(\text { total } / \text { mensal })}{N} \rightarrow$ DARme (mensal) $=\frac{147,291.00}{33}$, ou seja, dividindo a DARtotal pelo número de respondentes, a DARme (mensal) foi de $\mathrm{R} \$ 4,463.36$ por pessoa/mês.

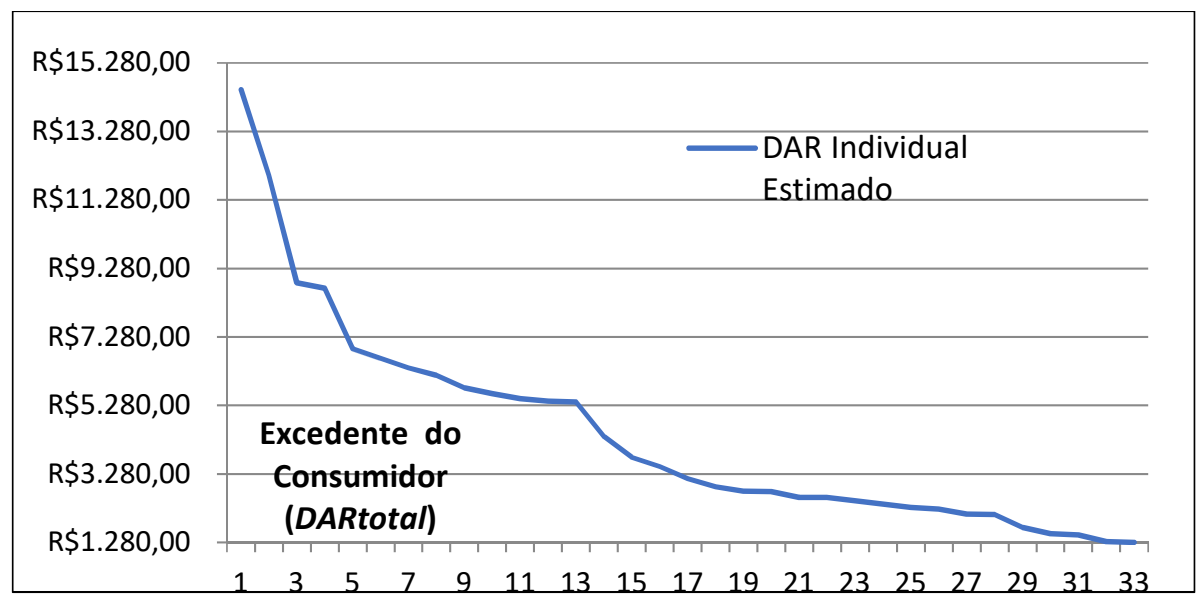

Figura 2: Disposição a Receber Marginal Estimada dos Respondentes.

O valor da DARMe (anual), obtida multiplicando a DARMe (mensal) por 12 meses: DARme (anual) = DARme (mensal) * No de meses do Ano; DARme (anual) $=\mathrm{R} \$ 4,463.36 * 12$, o que dá um valor de $\mathrm{R} \$ 53,560.36$ por pessoa/ano. A estimativa do fluxo benefícios derivados a partir dos bens ambientais extraídos do manguezal pela comunidade local é obtido multiplicando-se a DARMe anual $(\mathrm{R} \$ 53,560.36)$ pelo número de usuários $\left(415\right.$ pessoas $\left.^{10}\right)$ desse ecossistema, e dividindo este valor pela taxa de desconto ${ }^{11}$ $(12,88 \% \text { a.a. })^{12}$.

Tem-se EFB $=\frac{\text { DARme(anual) } * \text { No de usuários }}{\text { Taxa de Desconto }} \rightarrow E F B=\frac{\mathrm{R} \$ 53,560.36 * 415}{0,1288}$, e desta forma, o valor atual do somatório do fluxo de benefícios futuros derivados do uso direto consuntivo dos manguezais, representado aqui pela disposição a receber remuneração, é estimado em $\mathrm{R} \$ 172.574 .153,02$. Este valor representa quanto as comunidades obteriam de benefícios pelo uso direto e indireto dos manguezais em perpetuidade considerando também o valor de não uso (existência). Dividindo o valor atual do fluxo de benefícios pela área do manguezal na foz do Rio que banha a Vila de São João no município de São Miguel de Odivelas (PA), equivalente a 950ha e convertendo para a moeda americana - taxa de câmbio ${ }^{13}$ de $R \$ 3,64$ por dólar: VERA(VUD) $=\frac{E F B(R \$)}{\text { ÁreadoEcossistema(Ha) }} / e(U S \$) ; V E R A(V U D)=\frac{R \$ 11.362 .843,33}{1.154(h a)} / 1,72$.

Obtém-se US\$49.905,77/ha/ano, o que equivale, em reais à $R \$ 181.657,00 /$ ha/ano. Relativizando os valores acima por família e por pessoas, em dólar e reais, estima-se, por família em US\$601,27 / R\$2.188,64 e por pessoa em US\$120,25 / R\$437,73, respectivamente. Logo, este valor corresponde aos valores médios,

\footnotetext{
${ }^{10}$ Nessa estimativa considerou-se o total de 83 famílias multiplicada pela média do número de pessoas residentes no domicílio, equivalente aproximadamente a 5 pessoas por residência.

${ }^{11}$ A taxa de desconto permite comparar os fluxos de valores monetários ao longo do tempo e reflete a preferência temporal pura, ou seja, a impaciência das pessoas por dinheiro hoje ao invés de no futuro.

12 Taxa de juros selic válida para o período/dia da estimação, disponibilizada pelo BACEN do Brasil.

${ }^{13}$ Taxa de Câmbio Nominal: $e=\frac{R \$}{U S \$}$
} 
que cada família/pessoa deveria vir a receber por não fazer uso dos recursos ambientais provenientes no manguezal, sobretudo o caranguejo.

\section{CONCLUSÕES}

O manguezal da ilha São Miguel, foi valorado com a participação consciente da comunidade da Reserva Extrativista (Resex), sobretudo por parte dos catadores de caranguejo e pescadores, pessoas que utilizam o manguezal no seu dia a dia, seja para fins comerciais, seja para fins de sobrevivência. A maioria dos moradores da Comunidade Ilha São Miguel possui entre 20 e 39 anos, uma população economicamente ativa, cuja atividade econômica predominante é a coleta de crustáceos e mariscos, tendo como principais produtos em ordem de uso, o caranguejo, o turu e a pesca, tanto para consumo como para venda. A coleta, em menor escala, do mel, do siri e do sururu é geralmente para consumo ou por encomenda para venda.

A caracterização socioeconômica da comunidade da ilha de São Miguel, identificada principalmente pelas atividades no manguezal, deu margem para estimar o valor de seus usos diretos e indiretos, a partir das respostas dos participantes da pesquisa. Um outro importante indicador do padrão socioeconômico foi o nível de escolaridade dos chefes de família entrevistados, pois, a grande maioria tanto homens como mulheres têm o ensino fundamental incompleto, seguidos daqueles com ensino médio incompleto e o médio completo. Só uma pessoa, entre os entrevistados, tem o nível superior incompleto e um número considerável de pessoas que nunca estudou.

A realização da oficina com a apresentação dos princípios, conceitos e tendências econômicas sobre a valoração econômica do ecossistema manguezal foi de fundamental importância não apenas para o melhor entendimento das funções e da valoração do manguezal nos mais diversos usos, visando uma melhor resposta quanto às disposições a pagar e receber dos comunitários, mas também para a introdução e, consequentemente, a ampliação dos conhecimentos, acerca dos serviços ecossistêmicos realizados pelo Manguezal, além de estreitar a relação dos centros de pesquisa com a comunidade estudada.

O manguezal da ilha São Miguel apresentou a um valor estimado de US\$49.905,77/ha/ano, o que equivale, em reais $\mathrm{R} \$ 181.657,00 /$ ha/ano. Relativizando estes valores por família e por pessoas, em dólar e em reais: por família US\$583,59 / R\$ 2.124,27 e por pessoa em US\$116,72 / R\$424,85, (taxa de câmbio $\mathrm{R} \$ 3,64)$. Logo, este valor corresponde aos valores médios, que cada família/pessoa deveria vir a receber por não fazer uso dos recursos ambientais provenientes no manguezal, sobretudo o caranguejo.

De forma geral, comparando outros resultados com o valor estimado nesta pesquisa, conclui-se que o manguezal da Vila São Miguel, no município de São Caetano de Odivelas (PA) gerou um valor para o manguezal superior aos demais estudos voltados ao ecossistema. Porém, deve-se considerar que possa ter havido uma 'sobre-estimativa' desse valor em decorrência da assimetria na distribuição das remunerações propostas nos questionários e o fato de que os respondentes levaram em consideração também valores de opção e os valores não-uso (existência) ao revelarem suas respectivas DARs, o que teve uma grande influência no resultado. 
Isto é, os respondentes passaram a considerar não apenas o valor monetário equivalente ao lucro obtido pela atividade extrativista, mas também o valor ambiental e social do ecossistema, porque passaram a conhecer melhor o ambiente em que trabalham e os inúmeros benefícios que ele traz, para a sociedade e para a fauna e flora associada a ele. Consideraram sua importância como berçário e abrigo peixes, aves, crustáceos, mamíferos entre outros, o valor da sua flora na medicina e como emissora de oxigênio, ou seja, consideraram o ecossistema.

Além daquele aspecto, a experiência tem demonstrado que estimativas de valores baseados em disposição a receber compensação pela perda de um bem são maiores do que aqueles baseados em disposição a pagar para garantir um bem, o que poderia servir de objetos para pesquisas futuras naquele estuário. Por meio dos resultados encontrados nesta pesquisa, pode-se concluir que é alto o grau de importância dado pelos usuários em relação ao manguezal presente no estuário do Rio Mojuim, Mocapajuba e Maripanema, e eles têm noção dos fatores antrópicos que ameaçam a sustentabilidade desse ecossistema, destacando também a sazonalidade como marcador de suas atividades no manguezal, onde, no inverno, os homens vão ao manguezal e no verão as mulheres, normalmente, acompanham homens.

\section{REFERÊNCIAS}

CASTRO, F. T. C.; ARAUJO, R. C. P.; SOUSA, H. C.. Valoração Econômica dos Usos Diretos do Ecossistema Manguezal: O Caso da Foz do Rio Jaguaribe. In: ENCONTRO DA SOCIEDADE BRASILEIRA DE ECONOMIA, ADMINISTRAÇÃO E SOCIOLOGIA RURAL, XLVIII. Anais. Campo Grande: UFMG, 2010.

MAY, P. H.; LUSTOSA, M. C.; VINHA, V.. Economia do Meio Ambiente. 2 ed. São Paulo: Campus, 2010.

MOTA, J. A.. O Valor da Natureza: economia e política dos recursos naturais. 2 ed. Rio de Janeiro: Garamond, 2006.

MOTTA, R. S.. Manual para Valoração Econômica de Recursos Ambientais. Brasília: IPEA, 1998.

MOURA, L. A. A.. Economia Ambiental: gestão de custos e investimentos. São Paulo: Juarez de Oliveira, 2000.

NANNI, H. C.; NANNI, S. M.. Preservação dos manguezais e seus reflexos. In: Simpósio de Engenharia de Produção, 12 Anais. Bauru: UNESP, 2005b.

NANNI, H. C.; NANNI, S. M.; SEGNINI, R. C.. A importância dos manguezais para o equilíbrio ambiental. In: SIMPÓSIO INTERNACIONAL DE CIENCIAS INTEGRADAS DA UNAERP CAMPUS GUARUJÁ, XLVIII. Anais. Ribeirão Preto: UNAERP, 2005a.
ORTIZ, R. A.. Valoração Econômica Ambiental. In: MAY, P. H.; LUSTOSA, M. C.; VINHA, V.. Economia do Meio Ambiente. 2 ed. São Paulo: Campus, 2010.

PICANÇO, M. S. M.. A Formação Vegetal do Município de São Caetano de Odivelas (PA), por meio de produtos de sensoriamento remoto. Revista GeoNorte, Manaus, p.113124, 2012.

PINDYCK, R. S.; RUBINFELD, D. L.. Microeconomia. 7 ed. Nova Jersey: Prentice-Hall, 2010.

PROST, M. T.. Manguezais e Estuários da Costa Paraense: Exemplo de estudo multidisciplinar integrado (Marapanim e São Caetano de Odivelas). In: PROST, M. T.; MENDES, A. C.. Ecossistemas Costeiros: Impactos e gestão ambiental. Belém: MPEG, 2001. p.75-87.

VARIAN, H. R.. Microeconomia: princípios básicos. 8 ed. São Paulo: Campus, 2012.

VASCONCELLOS, M. A. S.; OLIVEIRA, R. G.. Manual de Microeconomia. 3 ed. São Paulo: Atlas, 2011.

A CBPC - Companhia Brasileira de Produção Científica (CNPJ: 11.221.422/0001-03) detém os direitos materiais desta publicação. Os direitos referem-se à publicação do trabalho em qualquer parte do mundo, incluindo os direitos às renovaç̃̃es, expansões e disseminações da contribuição, bem como outros direitos subsidiários. Todos os trabalhos publicados eletronicamente poderão posteriormente ser publicados em coletâneas impressas sob coordenação da Sustenere Publishing, da Companhia Brasileira de Produção Científica e seus parceiros autorizados. Os (as) autores (as) preservam os direitos autorais, mas não têm permissão para a publicação da contribuição em outro meio, impresso ou digital, em português ou em tradução. 